solubilisation. In this context it is interesting that Fambrough (Neurochemistry of Cholinergic Receptors, edit. by E. de Robertis, Raven Press, New York) observed that clusters of toxin-labelled receptors on cultured chick muscle cells could be dispersed by $0.01 \%$ Triton, although this treatment did not solubilise the receptors or irreversibly damage the membrane.

It seems that to establish the membrane characteristics which are responsible for the stability of the endplate it will be necessary not only to investigate the structure of the receptor protein itself, but also to look more closely at the involvement of other membrane components in the intact tissue.

\section{Conservation of nitrogen in climax ecosystems}

\section{from Peter D. Moore}

Climax ecosystems possess several attributes which lead to an increased conservation of essential nutrients; for example, nutrients generally become concentrated in the biota, and nutrient output from the system is low in comparison to this biotic reservoir (Bormann, Likens and Eaton, Bioscience, $19,600 ; 1969)$. In a series of papers, Rice and Pancholy (Am. J. Bot., 59, $1033 ; 1972$ and 60,$691 ; 1973$ ) have now suggested that certain climax vegetation types may inhibit nitrification by soil microbes, as a result of the production of toxins in the litter, thus reducing the rate of nitrate production and loss.

In the process of nitrification ammonium ions are oxidised by microbes in two stages to nitrite and then to nitrate, in which form nitrogen is more readily available to the majority of plants. In this form, however, nitrogen is easily lost from ecosystems since, being anionic, it is not retained well by clay colloids in the soil. Rice and Pancholy therefore regard the suppression of nitrification as a mechanism whereby nitrogen is retained within the ecosystem.

They were led to this position initially by a number of reports concerning grassland habitats in which low activities of the nitrifying bacteria and very low nitrate levels were found. Theron (J. Agric. Sci., Cambs., 41, 289; 1951) had suggested that grass roots could secrete a toxin which might affect nitrification and, in African grasslands, Boughey et al. (Nature, 203, 1302; 1964) suggested that the secretion of toxic substances by the grass Hyparrhenia could explain many aspects of the ecology of these habitats. Rice and
Pancholy followed up these ideas in an old field succession in Oklahoma by measuring ammonium and nitrate levels in soils from various stages in the succession.

They showed high nitrate levels in the early stages falling to low levels at the climax, with ammonium ions behaving in a reciprocal fashion. They also found that the density of Nitrosomonas and Nitrobacter (the nitrifying bacteria) in the soil fell during the course of succession. In 1973 they published further data implicating tannins and their derivatives as possible agents in the suppression of nitrification and showed that tannin levels were highest in the climax soils. Particularly surprising were the high tannin concentrations in grassland soils and in the litter produced by grasses. This, they felt, could account for the low nitrate levels found in many grasslands, particularly since Nitrosomonas activity is inhibited by tannin levels of only 2 p.p.m., less than half the lowest recorded soil concentration in grasslands. Nitrobacter (which oxidised nitrite to nitrate) was less sensitive, but suppression of one step would effectively block nitrification.

Recently (Am. J . Bot., 61, 1095; 1974) they have attempted the separation and identification of the precise inhibitors which may be involved and, by analysing acetone extracts of plants and soil, have come to the conclusion that many compounds in addition to tannins could be active in suppression, mainly phenolic acids and phenolic glycosides. All were more effective in suppressing Nitrosomonas than in the inhibition of Nitrobacter.

Meanwhile, back in the African grasslands, more work has been in progress on the suggested inhibitory properties of Hyparrhenia; Purchase (Plant Soil, 41, 527; 1974) has added the washings of this grass to soils and has checked the progress of nitrification. After 13 days nitrate production began to fall, but Purchase regards this as the result of increased acidity, since addition of $\mathrm{CaCO}_{3}$ to the water led to continued nitrate production. Eluate of the soils seemed not to influence the activity of test Nitrobacter cultures, but Rice and Pancholy have shown that the nitrite to nitrate stage of the oxidation is less sensitive to inhibitors. Nitrate production was depressed when Hyparrhenia root macerate was added to soils, but Purchase puts this down to immobilisation of the mineral nitrogen by the presence of root tissue, since there was no build-up of ammonium ions which one might expect if the nitrifying bacteria were suppressed. Purchase considers the scarcity of nitrifying bacteria in Hyparrhenia grassland soils to be due to the immobilisation of ammonium ions by root tissue, hence robbing the microbes of a substrate.

Chase, Corke and Robinson (in The Ecology of Soil Bacteria, edit. by T. R. G. Gray and D. Parkinson, 593; Liverpool University Press, 1967) have come to the conclusion that in some soils low $p \mathrm{H}$ and phosphate deficiency may limit nitrification. Using perfusion techniques they showed that nitrification could be induced in infertile grassland soils, perfused with ammonium sulphate, by the addition of lime and phosphate. Purchase (Plant Soil, 41, $541 ; 1974)$ has also investigated the possibility that the savanna grassland soils could be deficient in nitrifying bacteria because of low phosphate levels, even when ample ammonium ions are available. He added ammonia to soils with varying degrees of phosphate deficiency and found that the nitrification resulting was closely related to the amount of available phosphorus in the soil. He concludes that phosphate deficiency in savanna soils could account for the restricted nitrification, the nitrite oxidisers being particularly sensitive. It is also possible that the grass roots themselves, together with associated rhizosphere microorganisms, are competing with the nitrifiers for phosphate, thus aggravating the deficiency. Robinson (Plant Soil, 19, 173; 1963) has suggested this sort of competition, but for ammonium ions, in New Zealand grasslands.

It is now well known that many higher plant species are able to absorb and utilise nitrogen in the form of ammonium ions. Recent work by Havill, Lee and Stewart (New Phytol., $73,1221 ; 1974)$ suggests that in some habitats where nitrate production is particularly low, such as acidic, ombrotrophic mires, many of the higher plants have a reduced capacity for nitrate utilisation, since their nitrate reductase activities are very low. Such species must depend upon ammonium ions as their major source of nitrogen. As Rice and Pancholy have pointed out, this mechanism not only bypasses the microbial nitrification stage, which may reduce the risk of nitrate loss from the ecosystem, but also saves the plant the energy required for the activity of nitrate reductase. Whatever the mechanism whereby nitrification is suppressed in some ecosystems, and it is likely that the precise nature of the suppression varies from one ecosystem to another, the resulting nitrate scarcity has evidently placed a selective pressure upon the resident plant species, resulting in their ability to use ammonium ions. This evolutionary response and the suppressed nitrification which has engendered it, may well provide a mechanism for ecosystem nitrogen conservation. 